Baas, C.I., Wiegers, T.A., Cock, T.P. de, Erwich, J.J.H.M., Spelten, E.R., Boer, M.R. de, Hutton,

E.K. Client-related factors associated with a "Less than Good" experience of midwifery care

during childbirth in the Netherlands. Birth: Issue in Perinatal Care: 2017, 44(1), 58-67

nivel

\begin{tabular}{|l|l|}
$\begin{array}{l}\text { Postprint } \\
\text { Version }\end{array}$ & 1.0 \\
\hline Journal website & http://onlinelibrary.wiley.com/doi/10.1111/birt.12266/abstract \\
\hline Pubmed link & https://www.ncbi.nlm.nih.gov/pubmed/27905662 \\
\hline DOI & $10.1111 /$ birt.12266 \\
\hline
\end{tabular}

This is a NIVEL certified Post Print, more info at http://www.nivel.eu

\title{
Client-Related Factors Associated with a "Less than Good" Experience of Midwifery Care during Childbirth in the Netherlands
}

CArien I. BAAs, RM, Msc, Therese A. Wiegers, PhD, T. PAul De Cock, PhD, JAN JAAP H. M. ERWich, MD, PhD, Evelien R. SPElten, PhD, Michiel R. DE BOER, PhD, AND EILEEN K. HutTON, RM, PHD

\begin{abstract}
Background: A "less than good" experience during childbirth can affect a mother's early interaction with her child and may significantly influence a woman's emotional well-being. In this study, we focus on clients who experienced midwifery care provided during childbirth as "less than good" care. The aim of this study was to understand the relationship between client-related factors and the experience of midwifery care during childbirth to improve this care. Methods: This study was part of the "DELIVER study" where mothers report on the care they received. We used generalized estimation equations to control for correlations within midwife practices. Forward multivariate logistic regression analyses were conducted to model the client-related factors associated with the experienced midwifery care during childbirth. Results: We included the responses of 2,377 women. In the multivariable logistic regression model, odds of reporting "less than good care" were significantly higher for women who experienced an unplanned cesarean birth (OR 2.21 [CI 1.19-4.09]), an instrumental birth (OR 1.55 [CI 1.08-2.23]), and less control during the dilation phase (OR 0.98 [CI 0.97-0.99]) and pushing phase (OR 0.98 [CI 0.970.99]). Discussion: Birth-related factors were more likely than maternal characteristics to be associated with the experience of midwifery care during childbirth. We conclude that there is room for midwives to improve their care for women during childbirth particularly in improving the patient centeredness of the care provider, using strategies to enhance sense of control, and focusing on the particular needs of those who experience instrumental vaginal or unplanned cesarean births. (BIRTH 2016)
\end{abstract}

A "less than good" experience with childbirth can affect a mother's early interaction with her child and may significantly influence women's emotional wellbeing in the short and longer term, even contributing to post-traumatic stress or depressive mood disorders $(1,2)$. Many factors influence women's experience of childbirth 
including: age, parity, social status, expectations, prenatal education, being informed, experience of control, pain, mode of birth, medical interventions, experienced support of caregivers and partner and duration of labor, and the birth environment (3-5).

Although care provided by the maternity care provider during childbirth can be an important factor contributing to a positive childbirth experience $(5,6)$, being satisfied with the childbirth experience is not the same as being satisfied with care experienced during childbirth. A woman can be satisfied with her own accomplishment and look back positively on childbirth, but not be satisfied with the care she experienced during her birth. In this study, we focus on clients who experienced midwifery care provided during childbirth as "less than good" care. In the Netherlands, the maternity care system consists of primary and secondary and tertiary care. Healthy women with a normal pregnancy will see a primary care midwife (and no other care provider) during pregnancy and she can choose to give birth at home or in the hospital. During childbirth and the postpartum period, a primary care midwife will provide care assisted by a maternity care assistant in the community or a nurse in hospital. Only when problems occur during pregnancy or childbirth are women referred to secondary care for consultation with, or referral to an obstetrician.

Most research about birth satisfaction focuses on women with high levels of satisfaction; few studies are powered to consider those women with lower levels of satisfaction (6-9). Focusing purely on satisfaction with the experienced care may miss the separate but illuminating construct of patient dissatisfaction (8), which may highlight problems and inform areas for improvement in the maternity care system (8-10).

The aim of this study is to understand the relation between client-related factors and the experience of intrapartum midwifery care to give midwives an insight into how they might improve the care they provide during childbirth.

Our main research question was as follows: do women who report "less than good" care from their midwife during childbirth differ from women who report "good to best possible" care from their midwife during childbirth in terms of: age, parity, ethnic background, socioeconomic status, living situation (marital status), education level, employment status, whether the pregnancy was planned, symptoms of anxiety or depression postpartum, mode of birth, experienced sense of control during the dilation and pushing phase, and the experienced patient centeredness of the care provider?

\section{METHODS}

This study is part of the DELIVER study, which is a large prospective cohort study in the Netherlands set up to investigate the organization, accessibility, and quality of primary midwifery care. Data were collected from clients and their partners, midwives, and other health care professionals across the Netherlands, between September 2009 and April 2011. Clients from 20 midwifery practices assessed their expectations and experiences. These client data were linked to data from electronic client records kept by midwives and collected by the Netherlands Perinatal Register. Methodological details of this study have been published previously (11). The Medical Ethics Committee of VU University Medical Centre, Amsterdam approved the study protocol of the DELIVER study. 


\section{Participants, Setting, and Procedure}

Participants of our study were women with uncomplicated pregnancies within the DELIVER study population in the Netherlands. The DELIVER study recruited for a 1 -year period and depending on when clients began their participation, they may have completed up to three questionnaires at different time points: one questionnaire in the early prenatal period (around 20 weeks of pregnancy), one questionnaire in the late prenatal period (around 34 weeks of pregnancy), and one questionnaire postpartum (around 6 weeks postpartum). Data from the different questionnaires were linked at the personal level. We included all women who responded to the postpartum questionnaire. To focus on primary care providers, we excluded women who began labor in secondary or tertiary care.

\section{Measures}

The main outcome variable, the experience of midwifery care provided during childbirth, was measured using a summary rating scale in the postpartum questionnaire which asked participants to: "Please rate your overall feelings about the care provided by your midwife during labor and birth on a scale from 1 to 10 , with one indicating the worst possible care and 10 indicating the best possible care." The rating scale functions as a summary: the final question after a set of questions about various aspects of the care received during childbirth. A similar rating scale is a standard item in patient and consumer experience questionnaires, such as the Consumer Quality Index questionnaires (12). For analysis, the outcome variable, the experience of midwifery care during childbirth (a rating between 1and 10) was dichotomized. We dichotomized the outcome variable into "less than good" care (rating 1-7) and "good to best possible" care (rating 8-10). This distribution is based on the Dutch school system, where an 8 or above indicates a good to excellent performance and a 7 or less indicates a moderate or bad performance (13). The client-related factors potentially correlated with the experience of midwifery care were derived from the literature (3-5). Participants provided information about their background characteristics including age, parity, education level, employment status, socioeconomic status, and living situation (marital status); ethnic background; and whether the pregnancy was planned or not.

In the questionnaire at 6 weeks postpartum, information was asked about symptoms of anxiety or depression, mode of birth, the experienced sense of control, and the experienced patient centeredness of the care provider during childbirth.

The client-related factors were dichotomous or categorical variables: parity (nulli- vs multiparous), employment status (employed vs unemployed), having a partner (yes vs no), whether the pregnancy was planned or not, perception to influence your health (yes vs no), and symptoms of anxiety or depression around 6 weeks postpartum (not at all vs somewhat/ very); and age $(<25,25-35,36+)$, education (low included elementary education, or pre-vocational secondary education, middle included secondary education preparing for universities of applied science and research universities, high included bachelor-equivalent or above), ethnic background (native Dutch, Western non-Dutch, non-Western), and mode of birth, categorized as spontaneous vaginal, instrumental vaginal, or cesarean section. The variable "socioeconomic status" consists of four categories of postal code areas. The research organization social cultural planning ordered all the postal codes in the Netherlands from low to high, based on average income, percentage of households with a low income, number of unemployed people, and percentage of households 
with low educational level. Using this information, the postal codes were divided into quartiles to form a categorical variable (14).

Sense of control was measured, using a shortened version of the Labour Agentry Scale $(10,11)$. The shorter version of the Labour Agentry Scale contains 10 items, and has an internal consistency coefficient of 0.97 and evidence of construct validity (15). We used the Labour Agentry Scale-10 to gain insight into feelings of control during both the dilation and pushing stage of labor. The translation into Dutch resulted in 11 items, because the English item "I felt helpless (powerless)" was translated into two separate items because of the substantive difference in meaning between "helpless" and "powerless" in the Dutch language. The 11 items concerning feelings of control were rated on a 7- point scale (from "almost never" [1] to "almost always" [7]) (11). The Labour Agentry Scale was analyzed, using the summated score. The experienced patient centeredness of the midwife was measured using a patientcenteredness scale in which the questions are based on quality indicators about treatment by a particular caregiver at a particular time (for example: Did your midwife listen to you carefully? Did your midwife take you seriously?). The patientcenteredness scale contains seven items measuring frequency on a 4-point scale ("never" [1], "sometimes" [2], "usually" [3], and "always" [4], and has an internal consistency coefficient of 0.9. The patient-centeredness scale was analyzed, as required, using the mean score (sum score divided by 7 , yielding a continuous variable with a score ranging between 1.0 and 4.0) (12).

\section{Analyses}

We compared the client-related factors at baseline between clients who experienced midwifery care provided during childbirth as "less than good" (rating 1-7) with those who experienced the care as "good to best possible" (rating 8-10) (see Table 1). The Pearson's chi-squared test was used to analyze categorical variables, and because of a negatively skewed distribution of the Labour Agentry Scale and patientcenteredness scores, the Mann-Whitney U test was used to analyze continuous variables.

Three variables had $>1$ percent missing values: whether the pregnancy was planned or not, symptoms of anxiety or depression, and control during childbirth (see Table $1)$; we first analyzed the complete cases $(n=1,754)$ followed by a missing value analysis. We observed that 29 percent of cases had missing data in at least one of the study variables.

We examined the variables with missing data by testing them for associations with other variables, using multiple logistic regression. These associations showed that the data were likely missing at random (MAR)(16). Thus, to minimize bias, multiple imputation was carried out, yielding a data set of 29 newly generated data sets (one for each $1 \%$ of respondents with missing data), each containing estimates of the missing data (17).

Our study consisted of two levels of data: midwife practices and individual pregnant women. We used generalized estimating equations, a method that provides standard errors adjusted for the repeated measurements from the same participant, using an exchangeable correlation structure, to control for correlations within midwife practices.

\section{[TABLE 1]}

Univariable and multivariable logistic regression analyses were conducted to model 
Baas, C.I., Wiegers, T.A., Cock, T.P. de, Erwich, J.J.H.M., Spelten, E.R., Boer, M.R. de, Hutton, E.K. Client-related factors associated with a "Less than Good" experience of midwifery care during childbirth in the Netherlands. Birth: Issue in Perinatal Care: 2017, 44(1), 58-67

the client-related factors independently associated with experience of midwifery care during childbirth. All characteristics mentioned in Table 2 were included in the univariable analysis. We used a forward procedure to analyze the factors in their multivariable context. The quasi-likelihood information criteria value determined model fit with the final multivariable model exhibiting the lowest quasi-likelihood information criteria value. The factor with a $\mathrm{p}$ value $\leq 0.05$ and the lowest quasilikelihood information criteria started as the first factor in the model. Each time a factor was added, the changes in all the remaining $\mathrm{p}$ values and quasi-likelihood information criteria were assessed.

Data were analyzed using SPSS 21.0 (SPSS Inc., Chicago, IL).

\section{RESULTS}

Of all 14,418 eligible clients of the participating midwifery practices, 7,685 clients participated by returning at least one questionnaire (response rate 53\%). For about only a quarter of these clients $(n=1,800)$, it would be possible to complete all three questionnaires during the 1-year study period. A total of 4,146 DELIVER participants completed Questionnaire 3, and after following our exclusion rules for this substudy, 2,377 participants remained (Fig. 1). Participants' mean age was 30.8 years (SD 4.5) and 45.2 percent were nulliparous and 54.8 percent multiparous (Table 1). The large majority of women were Native Dutch $(95.2 \%)$, had a partner (98.7\%), were employed (81.2\%), had a planned pregnancy $(84.9 \%)$ felt like they were greatly or very greatly able to influence their own health $(86.5 \%)$, had a spontaneous vaginal birth (87.1\%), and were not anxious or moody around 6 weeks postpartum $(81 \%)$. The mean score of the patient centeredness of the care provider during childbirth was 3.9 on a scale from 1.0 to 4.0. The experienced control during the dilation and the pushing phase on a scale from 11 to 77 was 60.87 and 58.51, respectively. More than half of the women were highly educated, while 34.2 percent had middle and 11.7 percent low education levels. Women were divided roughly equally between the quartiles of socioeconomic status.

\section{[TABLE 2]}

\section{[FIGURE 1]}

One hundred ninety-two women $(8 \%)$ experienced midwifery care during childbirth as "less than good," and 2,185 (92\%) women experienced the care as "good to best possible."

Compared with women who experienced "good to best possible" midwifery care, those who experienced "less than good" midwifery care during childbirth did not differ significantly in age, nationality, having a partner, education level, employment status, and planning of the pregnancy (Table 1). However, women who experienced "less than good" intrapartum midwifery care were more frequently nulliparous, had a lower socioeconomic status, were more anxious or moody around 6 weeks postpartum, felt less able to influence their own health, had more instrumental or cesarean births, and experienced less patient centeredness and control during childbirth (the dilation and pushing phase).

\section{Multivariable Analyses}

The complete case analyses performed on the original data set $(n=1,754)$ only 
showed a significant relation between control during the dilation and pushing phase and a "less than good" experience of care. The "patient centeredness of the caregiver during birth" was excluded from the multivariable model because of a very high correlation with the experience of midwifery care during childbirth. There was no collinearity between the remaining measures.

Using the multiple imputed data set, the univariable analyses found that parity, mode of birth, and the Labour Agentry (control) during the dilation and the pushing phase were significantly associated with the experience of midwifery care during childbirth (Table 2). In the multivariable logistic regression model, mode of birth and control during dilation and pushing phase during birth remained significant factors in explaining whether women experienced the care during childbirth as "less than good" or "good to best possible" care. The odds were higher to experience midwifery care as "less than good" for women with an unplanned cesarean birth (OR 2.21 [CI 1.19-4.09]), or instrumental birth (OR 1.55 [CI 1.08-2.23]), and women with less sense of control during the dilation phase (OR 0.98 [CI 0.97-0.99]) and pushing phase (OR 0.98 [CI 0.97-0.99]). The control during the dilation and pushing phase was coded as a continuous variable, where the OR shows the level of change per one unit of change in the dependent variable. This means that a woman with a Labour Agentry Scale score during the dilation phase of 77 has a 0.22 lower odds to rate the care during birth as "less than good care" than a woman with a Labour Agentry Scale score of 11 .

\section{DISCUSSION}

Women in this national study in the Netherlands, who started their birth in primary care, rated their midwifery care during childbirth with a mean rating of 8.9 (scale from 1 to 10) with 8 percent of the women indicating that they experienced "less than good" care. A high rating of care is typical for studies on birthing experiences (610). Childbirth is a multidimensional experience, influenced by, but not restricted to, the relationships with and care given by the health care professionals. We were interested in exploring client-related factors associated with "less than good" experience of midwifery care during childbirth.

One of our first observations was that the patient centeredness of the midwife during childbirth, as reported by women, almost fully explained rating of midwifery care. A more women-centered and individualized approach which keeps clients informed and actively involved in their care, would likely increase women's satisfaction with the maternity care experience $(18,19)$.

Our study demonstrated differences in experienced care in relation to mode of birth. We found that women who experienced an instrumental birth, reported intrapartum care by their midwife as "less than good" more often than women who experienced a spontaneous vaginal birth. Furthermore, women who had an unplanned cesarean section were even more likely to indicate that they had received "less than good" midwifery care during childbirth. The international literature is ambiguous with regard to the influence of mode of birth on the experience of childbirth or care during childbirth. Some studies have found that mode of birth itself plays an important role in the final feelings about childbirth (20-22). Other studies have found no association (23-25). As women with an unplanned cesarean section or instrumental birth in this study will have had care transferred to other care providers during childbirth - most likely without their primary midwife staying on, it is possible that the discontinuity 
of care between the primary care midwife and the care providers in the secondary care system influenced the rating of midwifery care. An earlier Dutch study showed that referral during labor was significantly associated with reporting a negative childbirth experience (26), while another older study did not find a difference in satisfaction with the experience because of a referral during childbirth (27). It is possible that women's expectations for care during childbirth have changed over time.

To our knowledge, this was the first study that assessed the Labour Agentry scores among women who experienced the care from their midwife during childbirth as "less than good." Our finding that women with a lower sense of control during the dilation and during the pushing phase of childbirth were more likely to indicate that they experienced "less than good" midwifery care parallels the international literature about control during birth. A woman's sense of control during childbirth is internationally consistently described as a major contributing factor to a woman's childbirth experience and her subsequent well-being (3,20,23,28-31).

Parity was not significantly associated with the experience of midwifery care; however, this might represent a type two error resulting from limited power to consider this variable. Birth-related factors were associated with the experience of midwifery care during childbirth more than maternal characteristics. In our sample, age, nationality, having a partner, employment status, planning of the pregnancy, socioeconomic status, and feeling able to influence your own health, were not associated with the experience of midwifery care during childbirth. This is in line with the results of a review by Hodnett et al who described that "personal expectations, the amount of support from caregivers, the quality of the caregiverpatient relationship, and involvement in decision-making, appear to be so important that they override the influence of background and other characteristics, when women evaluate their childbirth experience" (3).

The outcomes of this study highlight areas of midwifery care that could improve the experience of women during childbirth. To improve a woman's sense of control during childbirth, several studies showed that informing women of options and choices available and involving them in decision-making helped women feel more in control $(32,33)$. For example, a Dutch study found that having an influence on birthing positions in labor, home birth, and shared decision-making contributed to women's sense of control (1). A study from Green et al reported that "the ways in which women are helped to deal with pain will affect internal control; the extent to which they feel that they are actually cared about, rather than care being something that is done to them, will affect external control" (30). Future research should consider how to address the unmet needs of women who undergo instrumental or unplanned cesarean birth, including, for example, approaches to enhance a sense of control, such as extra attention and time, information, involvement in decisionmaking, continuity of primary care provider, and debriefing the birth experience. Strengths of our study include the large sample size, which for the most part is representative of the Dutch population of birthing women in the Netherlands in 2010 (mean age: 31.0 [SD 5.0]; 47.5\% nulliparous and 52.5\% multiparous). Compared with the general population of Dutch women between 15 and 45 years of age, women in our study had a higher level of education (28.2\% tertiary level of education vs 22.7 $\%)$ and were less likely to be from ethnic minority groups (9.6\% Western and $13.1 \%$ non-Western) $(34,35)$. 
Our data set is very complete with only three variables having more than 1 percent missing data. To minimize any biases that these missing data might introduce, we used multiple imputation analyses, which are considered superior to limiting analyses to complete cases $(36,37)$. A possible limitation in our study was that precoded scales asking for an overall rating of the care experienced may have underestimated the extent of dissatisfaction with particular aspects of care (22). However, our analyses showed that the rating scale is an adequate representation of the larger patientcenteredness scale, which includes seven separate aspects of client-centered care. In addition, because we asked women to rate the childbirth care at 6 weeks postpartum, there could have been a "haloeffect," whereby the experience of care may be difficult to separate from the outcome of childbirth as such, and be biased by the happy encounter with the newborn baby. This may have contributed to an underestimation of the overall number of women who experienced a "less than good" experience of midwifery care. It is likely, however, that those who were least satisfied were captured in the study. We conclude that birth-related factors are associated with the experience of midwifery care during childbirth more than maternal characteristics. And although the vast majority of women were satisfied with the care that they received during childbirth, there is room for midwives to improve care specifically using strategies to enhance sense of control and focussing on the particular needs of those who go on to experience instrumental or unplanned cesarean birth.

Acknowledgments

We thank the clients, their partners, and the midwives for their time and effort to participate in the DELIVER study. Furthermore, we thank the KNOV (the Royal Dutch Organization of Midwives) for their PhD scholarship.

\section{REFERENCES}

1. Nieuwenhuijze MJ, de Jonge A, Korstjens I, Lagro-Janssen TLM. Influence on birthing positions affects women's sense of control in second stage of labour. Midwifery 2013;29(11):e107-e114.

2. Howarth AM, Swain N, Treharne GJ. Taking personal responsibility for well-being increases birth satisfaction of first time mothers. J Health Psychol 2011;16:1221.

3. Hodnett ED. Pain and women's satisfaction with the experience of childbirth: A systematic review. Am J Obstet Gynecol 2002;186:s160-S172.

4. Waldenstrom U, Borg I, Olsson B, et al The childbirth experience: A study of 295 new mothers. Birth 1996;23(3):144-153.

5. Bryanton J, Gagnon A, Johnston C, Hatem M. Predictors of women's perceptions of the childbirth experience. J Obstet Gynecol Neonatal Nurs 2008;37:24-34.

6. Waldenstrom U, Rudman A. Satisfaction with maternity care: How to measure and what to do. Women's Health 2008;4(3):211-214.

7. Fitzpatrick R. Capturing what matters to patients when they evaluate their hospital care. Qual Saf Health Care 2002;11:306.

8. Lee A, Moriarty J, Borgstrom C, Horwitz L. What can we learn from patient dissatisfaction? Analysis of dissatisfying events at an academic medical center. J Hosp Med 2010;5(9):514-520.

9. Redshaw M. Women as consumers of maternity care: Measuring "satisfaction" or "dissatisfaction"? Birth 2008;35(1):73-76.

10. Coyle J. Understanding dissatisfied users; developing a framework for comprehending criticisms of health care work. J Adv Nurs 1999;30(3):723-731.

11. Manni€en J, Klomp T, Wiegers T, et al Evaluation of primary care midwifery in The Netherlands: Design and rationale of a dynamic cohort study (DELIVER). BMC Health Serv Res 2012;20(12):69. doi:10.1186/1472-6963-12-69.

12. Wiegers TA. The quality of maternity care services as experienced by women in the Netherlands. BMC Pregnancy Childbirth 2009;9(9):18. doi:10.1186/1471-2393-9-18. 
Baas, C.I., Wiegers, T.A., Cock, T.P. de, Erwich, J.J.H.M., Spelten, E.R., Boer, M.R. de, Hutton, E.K. Client-related factors associated with a "Less than Good" experience of midwifery care during childbirth in the Netherlands. Birth: Issue in Perinatal Care: 2017, 44(1), 58-67

13. EP-Nuffic. Education system. The Netherlands, The Dutch education system described. Accessed May 23, 2016. https://www.ep nuffic.nl/en/publications/find-apublication/education-system-thenetherlands. pdf; 2015, version 4.

14. SCP (Social Cultural Planning). Statusscores. Accessed May 20, 2016 http://www.scp.nl/Onderzoek/Lopend_onderzoek/A_Z_alle_lopende_ onderzoeken/Statusscores.

15. Hodnett ED, Simmons-Tropea DA. The Labour Agentry Scale: Psychometric properties of an instrument measuring control during childbirth. Res Nurs Health 1987;10:301-310.

16. IBM. IBM SPSS missing values 20. Accessed May 20, 2016 http://www.sussex.ac.uk/its/pdfs/SPSS Missing Values 20.pdf.

17. White IR, Royston P, Wood AM. Multiple imputation using chained equations: Issues and guidance for practice. Stat Med 2011;30(4):377-399. doi:10.1002/sim.4067. Epub 2010 Nov 30.

18. Baas $\mathrm{Cl}$, Erwich JJ, Wiegers TA, et al Women's suggestions for improving midwifery care in the Netherlands. Birth 2015;42 (4):369-378. doi:10.1111/birt.12185.

19. Hildingsson I, Thomas JE. Women's perspectives on maternity services in Sweden: Processes, problems and solutions. J Midwifery Womens Health 2007;52(2):126-133.

20. Lewis L, Hauck YL, Ronchi F, et al Gaining insight into how women conceptualize satisfaction. Western Australian women's perception of their maternity care experiences. BMC Pregnancy Childbirth 2016;16(29):1-9.

21. Henderson J, Redshaw M. Who is well after childbirth? Factors related to positive outcome. Birth 2013;40(1):1-9.

22. Bramabad IJ, Dreidger M. Satisfaction with childbirth: Theories and methods of measurement. Birth 1993;20(1):22-29.

23. Fair CD,Morrison TE. The relationship between prenatal control, experienced control, and birth satisfaction among primiparous women. Midwifery 2011; doi:10.1016/j.midw.2010.10.013.

24. Spaich S, Welzel G, Berlit S, et al Mode of delivery and its influence on women's satisfaction with childbirth. Eur J Obstet Gynecol Reprod Biol 2013; 170: 401-406.

25. Hildingsson I. Women's birth expectations, are they fulfilled? Findings from a longitudinal Swedish cohort study. Women Birth 2015;28:e7-e13.

26. Rijnders $\mathrm{M}$, Baston $\mathrm{H}$, Sch€onbeck $\mathrm{Y}$, et al Perinatal factors related to negative or positive recall of birth experience in women 3 years postpartum in the Netherlands. Birth. 2008;35(2):107-116.

27. Wiegers TA, van der Zee J, Keirse MJ. Transfer from home to hospital: What is its effect on the experience of childbirth? Birth 1998;25(1):19-24.

28. Waldenstrom U, Hildingsson I, Rubertsson C, Radestad I. A negative birth experience; prevalence and risk factors in a national sample. Birth 2004;31(1):17-27.

29. Goodman P, Mackey MC, Tavakoli AS. Factors related to childbirth satisfaction. J Adv Nurs 2004;46(2):212-219.

30. Green JM, Baston HA. Feeling in control during labor: Concepts, correlates, and consequences. Birth 2003;30(4):235-247.

31. Brown S, Lumley J. Satisfaction with care in labor and birth: A survey of 790 Australian women. Birth 1994;21(1):4-13.

32. Seguin L, Therrien R, Champagne F, Larouche $D$. The components of women's satisfaction with maternity care. Birth 1989;16 (3):109-113.

33. Gibbins J, Thomson AM. Women's expectations and experiences of childbirth. Midwifery 2001;17:302-313.

34. PRN, Stichting Perinatale Registratie Nederland (Netherlands Perinatal Registry), 2010. http://www.perinatreg.nl/uploads/150/ 153/PRN_jaarboek_2010_09122014.pdf.

35. CBS, centraal bureau voor de statistiek, Statistics Netherlands 2010: http://statline.cbs.nl/StatWeb/publication/?DM=SLNL\&PA $=71822 \mathrm{NED} \& D 1=0 \& \mathrm{D} 2=\mid \& \mathrm{D} 3=0,4-5 \& \mathrm{D} 4=0-4 \& \mathrm{D} 5=\mathrm{a} \& \mathrm{D} 6=0$ \& $\mathrm{D} 7=9 \& \mathrm{HDR}=\mathrm{T}, \mathrm{G} 2, \mathrm{G} 1, \mathrm{G} 5, \mathrm{G} 6 \& \mathrm{STB}=\mathrm{G} 4, \mathrm{G} 3 \& \mathrm{VW}=\mathrm{T}$

36. White IR, Carlin JB. Bias and efficiency of multiple imputation compared with completecase analysis for missing covariate values. Stat Med 2010;29:2920-2931 
Baas, C.I., Wiegers, T.A., Cock, T.P. de, Erwich, J.J.H.M., Spelten, E.R., Boer, M.R. de, Hutton, E.K. Client-related factors associated with a "Less than Good" experience of midwifery care during childbirth in the Netherlands. Birth: Issue in Perinatal Care: 2017, 44(1), 58-67

37. Donders ART, van der Heijden GJ, Stijnen T, Moons KG. Special series: Missing dat. review: A gentle introduction to imputation of missing values. J Clin Epidemiol 2006;59:1087- 1091.

\section{TABLES AND FIGURES}

Table 1. Client-Related Characteristics of the Participants in the "DELIVER" Study, Who Responded to Questionnaire 3 and Who Started Their Birth in Primary Care, the Netherlands, 2009-2011. Original Data Set.

\begin{tabular}{|c|c|c|c|}
\hline & $\begin{array}{c}\text { Total } \\
\mathrm{N}=2,377(\%)\end{array}$ & $\begin{array}{l}\text { "Less than good" care; } \\
\text { rating between } 1 \text { and } 7 \\
\mathrm{n}=192(\%)\end{array}$ & $\begin{array}{c}\text { "Good to best poss ble" care; } \\
\text { rating bewween } 8 \text { and } 10 \\
\mathrm{n}=2,185(\%)\end{array}$ \\
\hline \multicolumn{4}{|l|}{ Age } \\
\hline$<25$ & $181(7.6 \%)$ & $15(7.8 \%)$ & $166(7.6 \%)$ \\
\hline $25-35$ & $1,840(77.4 \%)$ & $146(76.0 \%)$ & $1,694(77.6 \%)$ \\
\hline$>35$ & $355(14.9 \%)$ & $31(16.1 \%)$ & $324(14.8 \%)$ \\
\hline Missing & 1 & 0 & 1 \\
\hline \multicolumn{4}{|l|}{ Panity* } \\
\hline Nulliparous & $1,073(45.2 \%)$ & $111(57.8 \%)$ & $962(44.0 \%)$ \\
\hline Parous & $1,303(54.8 \%)$ & $81(42.2 \%)$ & $1,222(56.0 \%)$ \\
\hline Missing & 1 & 0 & 1 \\
\hline \multicolumn{4}{|l|}{ Nationality } \\
\hline Native Dutch & $2,260(95.2 \%)$ & $182(94.8 \%)$ & $2,078(95.2 \%)$ \\
\hline Westem non-Dutch & $59(2.5 \%)$ & $7(3.6 \%)$ & $52(2.4 \%)$ \\
\hline Non-Westem & $56(2.4 \%)$ & $3(1.6 \%)$ & $53(2.4 \%)$ \\
\hline Missing & 2 & 0 & 2 \\
\hline \multicolumn{4}{|l|}{ Partner } \\
\hline Yes & $2,341(98.7 \%)$ & $185(97.9 \%)$ & $2,156(98.8 \%)$ \\
\hline No & $31(1.3 \%)$ & $4(2.1 \%)$ & $27(1.2 \%)$ \\
\hline Missing & 5 & 3 & 2 \\
\hline \multicolumn{4}{|l|}{ Education level" } \\
\hline Low & $277(11.7 \%)$ & $18(9.5 \%)$ & $259(11.9 \%)$ \\
\hline Middle & $812(34.2)$ & $66(34.9 \%)$ & $746(34.2 \%)$ \\
\hline High & $1,282(54.1 \%)$ & $105(55.6 \%)$ & $1,177(53.9 \%)$ \\
\hline Missing & 6 & 3 & 3 \\
\hline \multicolumn{4}{|l|}{ Employment status } \\
\hline Employed & $1,931(81.2 \%)$ & $152(79.2 \%)$ & $1,779(81.4 \%)$ \\
\hline Other than employed & $446(18.8 \%)$ & $40(20.8 \%)$ & $406(18.6 \%)$ \\
\hline Missing & 0 & 0 & 0 \\
\hline \multicolumn{4}{|l|}{ Socioeconomic status } \\
\hline Quartile 1 high & $623(26.3 \%)$ & $49(25.8 \%)$ & $574(26.4 \%)$ \\
\hline Quartile 2 & $600(25.3 \%)$ & $33(17.4 \%)$ & $567(26.0 \%)$ \\
\hline Quartile 3 & $523(22.1 \%)$ & $54(28.4 \%)$ & $469(21.5 \%)$ \\
\hline Quartile 4 low & $621(26.2 \%)$ & $54(28.4 \%)$ & $567(26.0 \%)$ \\
\hline Missing & 10 & 2 & 8 \\
\hline \multicolumn{4}{|l|}{ Present pregnancy } \\
\hline Planned & $1,655(84.9 \%)$ & $130(84.4 \%)$ & $1,525(84.9 \%)$ \\
\hline Unplanned & $295(15.1 \%)$ & $24(15.6 \%)$ & $271(15.1 \%)$ \\
\hline Missing & 427 & 38 & 389 \\
\hline \multicolumn{4}{|c|}{ Anxious/moody postpartum* } \\
\hline Not at all & $1,178(81.0 \%)$ & $90(75.0 \%)$ & $1,088(81.6 \%)$ \\
\hline Somewhat/very & $276(19.0 \%)$ & $30(25.0 \%)$ & $246(18.4 \%)$ \\
\hline Missing & 923 & 72 & 851 \\
\hline
\end{tabular}


Baas, C.I., Wiegers, T.A., Cock, T.P. de, Erwich, J.J.H.M., Spelten, E.R., Boer, M.R. de, Hutton, E.K. Client-related factors associated with a "Less than Good" experience of midwifery care during childbirth in the Netherlands. Birth: Issue in Perinatal Care: 2017, 44(1), 58-67

Table 1 (continued)

\begin{tabular}{|c|c|c|c|}
\hline & $\begin{aligned} & \text { Total } \\
& \mathrm{N}=2,377(\%)\end{aligned}$ & $\begin{array}{l}\text { "Less than good" care; } \\
\text { rating between I and } 7 \\
\mathrm{n}=192(\%)\end{array}$ & $\begin{array}{l}\text { "Good to best passible" care; } \\
\text { rating between } 8 \text { and } 10 \\
\mathrm{n}=2,185(\%)\end{array}$ \\
\hline \multicolumn{4}{|c|}{ Feel able to influence own health } \\
\hline Much/very much & $2,047(86.5 \%)$ & $157(82.2 \%)$ & $1,890(86.9 \%)$ \\
\hline Hardly/not at all & $319(13.5 \%)$ & $34(17.8 \%)$ & $285(13.1 \%)$ \\
\hline Missing & 11 & 1 & 10 \\
\hline \multicolumn{4}{|l|}{ Mode of birth } \\
\hline Spontaneous vaginal & $2,057(87.1 \%)$ & $145(75.9 \%)$ & $1,912(88.1 \%)$ \\
\hline Instrumental vaginal & $229(9.7 \%)$ & $30(15.7 \%)$ & $199(9.2 \%)$ \\
\hline Cesarean section & $76(3.2 \%)$ & $16(8.4 \%)$ & $60(2.8 \%)$ \\
\hline Missing & 15 & 1 & 14 \\
\hline \multicolumn{4}{|c|}{ Intrapartum patient-centered ness scale* } \\
\hline Mean score (SD) & 3.85 & $3.22(0.713)$ & $3.91(0.25)$ \\
\hline Missing & 4 & 0 & 4 \\
\hline \multicolumn{4}{|c|}{ Labour Agentry Scale-Dilation phase* } \\
\hline $\begin{array}{l}\text { Mean composite } \\
\text { score (min-max) }\end{array}$ & $60.87(11-77)$ & $54.72(17-77)$ & $61.41(11-77)$ \\
\hline Missing & 95 & 9 & 86 \\
\hline \multicolumn{4}{|c|}{ Labour Agentry Scale-Pushing phase* } \\
\hline $\begin{array}{l}\text { Mean composite } \\
\text { score (min-max) }\end{array}$ & $58.51(11-77)$ & $51.38(11-77)$ & $59.10(11-77)$ \\
\hline Missing & 142 & 20 & 122 \\
\hline Total & 2,377 & 192 & 2,185 \\
\hline
\end{tabular}

Sturistically significant at $\mathrm{p}<.05$ kvel. ${ }^{\dagger}$ Educational level- Low - elementury education or pre-pocational secondury education; Middle - sec. ondary education prepares for universities of applied science and nesearch universities, High - bachebo or master degree. 
Baas, C.I., Wiegers, T.A., Cock, T.P. de, Erwich, J.J.H.M., Spelten, E.R., Boer, M.R. de, Hutton, E.K. Client-related factors associated with a "Less than Good" experience of midwifery care during childbirth in the Netherlands. Birth: Issue in Perinatal Care: 2017, 44(1), 58-67

Table 2. Client-Rekted Factors Associated with a "Less than Good" Experience of Midwifery Care during Childbirth Fixed Fffects, Multivariable Logistic Regression Analysis Using Generalized Estimation Equations, Forward Procedure, the Netherknds, 2009-2011. Multiple Imputed Data Set (29 data sets).

\begin{tabular}{|c|c|c|}
\hline Factor & $\begin{array}{c}\text { Cnude OR }(95 \% \text { CI) } \\
\text { Reference rating midwifery care } \\
\text { during childbirth with } 1-7\end{array}$ & $\begin{array}{c}\text { Adjusted OR }(95 \% \text { CI }) \\
\text { Reference rating midwifery care } \\
\text { during childbirth with } 1-7\end{array}$ \\
\hline \multicolumn{3}{|l|}{ Mode of birth } \\
\hline Cesarean section & $3.16(1.78-5.57)$ & $2.21(1.19-4.09)$ \\
\hline Instrumental vaginal & $1.99(1.42-2.79)$ & $1.55(1.08-2.23)$ \\
\hline Spontaneous vaginal & Reference & Reference \\
\hline Composite Labour Agentry score-Dilation phase & $0.96(0.95-0.97)$ & $0.98(0.97-0.99)$ \\
\hline Composite Labour Agentry score-Pushing phase & $0.96(0.96-0.97)$ & $0.98(0.97-0.99)$ \\
\hline \multicolumn{3}{|l|}{ Age } \\
\hline$<25$ & Reference & \\
\hline $25-35$ & $0.93(0.55-1.72)$ & \\
\hline$>35$ & $1.07(0.56-2.01)$ & \\
\hline \multicolumn{3}{|l|}{ Nationality } \\
\hline Non-Westem & $0.68(0.23-1.99)$ & \\
\hline Westem non-Dutch & $1.49(0.51-4.33)$ & \\
\hline Native Dutch & Reference & \\
\hline \multicolumn{3}{|l|}{ Parity } \\
\hline Parous & $0.58(0.42-0.80)$ & \\
\hline Nulliparous & Reference & \\
\hline \multicolumn{3}{|l|}{ Education level } \\
\hline 3 High & $1.23(0.69-2.20)$ & \\
\hline 2 Middle & $1.22(0.68-2.20)$ & \\
\hline 1 low & Reference & \\
\hline \multicolumn{3}{|l|}{ Partner } \\
\hline No Partner & $1.64(0.46-5.83)$ & \\
\hline Partner & Reference & \\
\hline \multicolumn{3}{|l|}{ Employment status } \\
\hline Unemployed & $1.16(0.85-1.59)$ & \\
\hline Employed & Reference & \\
\hline \multicolumn{3}{|l|}{ Socioeconomic status } \\
\hline Quartile 4 low & $1.10(0.86-1.39)$ & \\
\hline Quartile 3 & $1.40(0.93-2.10)$ & \\
\hline Quartile 2 & $0.71(0.45-1.11)$ & \\
\hline Quartile 1 high & Reference & \\
\hline \multicolumn{3}{|l|}{ Present pregnancy } \\
\hline Unplanned & $1.09(0.73-1.61)$ & \\
\hline Planned & Reference & \\
\hline \multicolumn{3}{|l|}{ Anxious'moody postpartum } \\
\hline Somewhat/very much & $1.58(1.12-2.23)$ & \\
\hline Not at all & Reference & \\
\hline \multicolumn{3}{|l|}{ Feel able to influence own health } \\
\hline Somewhat/very much & $0.71(0.51-0.90)$ & \\
\hline Hardly/not at all & Reference & \\
\hline Patient-centeredness scale composite score & $0.03(0.02-0.06)$ & \\
\hline
\end{tabular}

Significant outcomes in bold. 
Baas, C.I., Wiegers, T.A., Cock, T.P. de, Erwich, J.J.H.M., Spelten, E.R., Boer, M.R. de, Hutton, E.K. Client-related factors associated with a "Less than Good" experience of midwifery care during childbirth in the Netherlands. Birth: Issue in Perinatal Care: 2017, 44(1), 58-67

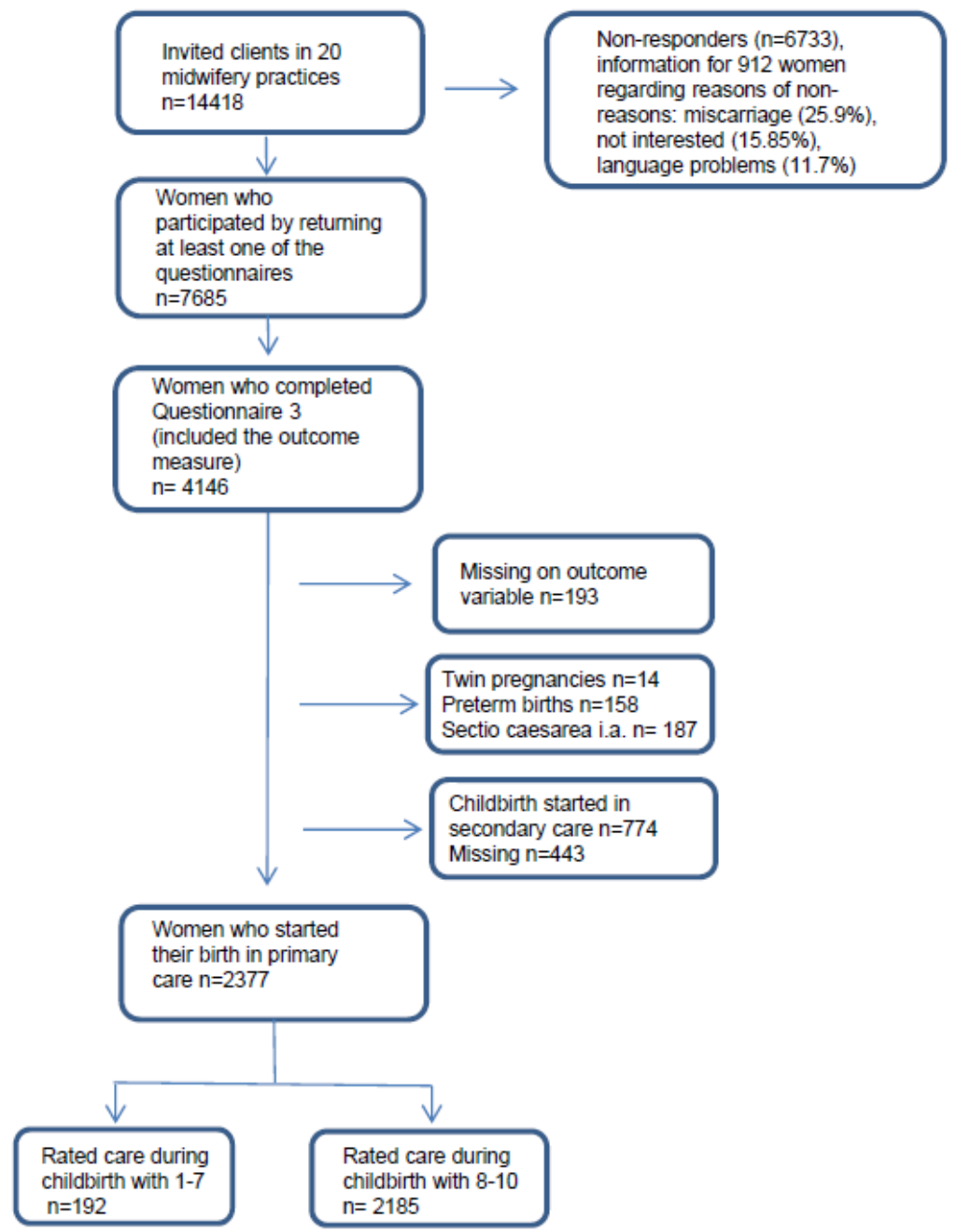

Fig. 1. Number of participants in the "DELIVER" study, who responded to Questionnaire 3 and who started their birth in primary care, the Netherlands, 2009-2011. [Color figure can be viewed at wileyonlinelibrary.com] 